of falling and striking that side? I cannot look upon the disease of the bone as causing the abscesses, as it would have been impossible for it to get to the situation over the occipital lobe. As regards the pus travelling down the neck, I fancy the counter-irritation to the neck might have determined it to take that course. 'Touching trephining, I do not think there were any symptoms indicative of intracranial suppuration until a few hours before death; and in reference to the pain in the hearl, I do not think there was sufficient locality about it, even if pus had been diagnosed, although Mr. Hulke was led into an erroneous conclusion in his cases as regards the pain and the seat of the abscess. On the other hand, we have the authority of Mr. Horsley and Dr. Ferrier to explore when in doubt, but $I$ honestly think, taking the above case on the whole, it was replete with obscurity and misleading in the extreme as regards the salient points of cerebral abscess.

\section{HOSPITAL FOR SICK CHILDREN, PENDLE- BURY, MANCHESTER.}

A CASE OF Otitis INTERNA AND CEREBELlar ABSCEss, IN WHICH THE SKULL WAS TREPHINED AND THE ADSCESS OPENED; NECROPSY.

(Under the care of Dr. Hutton and Mr. Wright.)

Fon the following account we are indebted to Mr. J. Hilton Thompson.

Benjamin MI_, aged eleven years. Six months before admission the patient had variola, followed by deafness on the left sicle and discharge from the right ear, which continued for more than five months, when the left ear commenced to discharge. On admission there was a purulent fetid discharge from both ears, destruction of both membrana tympani, and fungoid granulations at the bottom of the external auditory meatuses. From symptoms developed after admission it was decided that an abscess was situated either in the left temporo-sphenoidal lobe or in the left cerebellar hemisphere, and an operation was advised. The following is a short account of the operation, performed on July 13th : A circle of bone was removed with a trephine one inch and a half in diameter, the centre of the opening being about an inch behind a point two inches above the left external auditory meatus. The dura mater was divided by a crucial incision, and the exposed brain explored in various directions with a director, but without resnlt. Another opening was made with a gouge half an inch above the left superior curved line one inch and a half from the middle line, and an inch above the occipital protuberance. A trocar and cannula were passed through the opening downwards, piercing the occipital lobe and tentorium cerebelli into the cerebellum. On withdrawing the trocar about one drachm of thin fetid pus escaperl through the cannula; the latter was left in to serve as a drain, the guard of the cannula having been passed through to a slit in the flap. No paralysis resulted from the operation. Seven homs afterwards Cheyne-Stokes' respiration was noticed, and the patient died eight hours after the operation. The temperature just before death was $106^{\circ} 6^{\circ}$.

At the post-morten examination, the petrous portion of the left temporal bone was found extensively diseased, and perforated pis appeared to track backwards between thickened and adkerent dura mater beneath the left temporo-sphenoidal lobe towards the cerebellum; in the left hemisphere of the latter, was found a large abscess, occupying its posterior inferior and inner part. Some homorrhage was also found at the base of the brain.

The importance of such cases as the abore, from the influence they may have upon brain surgery, demands their being made public as soon as possible. The above abstract is inteniled as a preliminary notice; a more detailed account will be published at a later period.

CONSTANT WATER-STPPLY FOP THE CITY OF Losuos.-The Gas and Water Committee presented their report on a eonstant water-supply to the City, at a meeting of the Court of Cominon Council held last week. The inquiry was initiated in consequence of several petitions to the Cirurt on the question. The report enters fully and exhan-tively into the subject, and expresses, in conclusion, the opinion, on the facts and information they have obtained, that it is not expedient in the interests of the petitioners and the citizens generally, to take any steps in the direction indicated.

\section{athedical Sorititis.}

\section{ROYAL ACADEMY OF MEDICINE IN IRELAND.}

Specimens.-Removal of Uterine Appendage and Parovarian Tumour.-Peri-uterine Hamatocele.-Vesicular Mole.

A MeEting of the Obstetrical Section was held on May 25th.

Dr. W. J. SMyly exhibited a Hairpin which he had remored from the Bladder of a woman who came to the City of Dublin Hospital.

Dr. MACAN exhibited-1. A Fibrous Tumour and Uterus which he removed on May 2nd from a woman aged fortyeight in the Rotundo Hospital. When she first came in her uterus was of enormous size, and she complained of excessive hemorrhage. He determined to remove the tumour. He easily got the stump. The stump, however, unfortunately sank into the peritoneum and gave rise to acute sepsis, which caused her death on the 12 th of the month. 2. The remains of an Ovarian Tumour. It proved to be so absolutely rotten that he had to enlarge the incision in order to get command of it, and then to scoop it out in handfuls. It was afterwards obvious that there had been adhesions of the tumour to the intestines. on one occasion her temperature rose to $106^{\circ}$. He found her suffering from bronchitis. He inserted a drainage tube, through which a large quantity of perfectly harmless-looking and inodorous serum came away. The woman had been croing on very well since. 3. A specimen of an ordinary Ovarian Cyst. The only thing that made this specimen remarkable was that the case had been for a long time treated as one of ascites.

Dr. JoHN BYRNE exhibited a large Fibroma which he had removed from the uterus per vaginam. It was of an interstitial character, grew on the posterior wall of the uterus, and hung down into the vagina. The woman was thirty years of age. She had one child; her next parturition was an abortion, which was attended with fearful hæmorrhage. He put in a large pessary and sent her back to the country. While in the country she had another abortion, which was also attended with great hæmorrhage. When she returned to the hospital it was found that there was a tumour of such a size that no pessary would hold up her uterus. The tumour occupied the whole of the sacral space. She was chloroformed, and an incision was made close to the upper part of the vaginal wall, and after a good deal of tugging the tumour was got out. The woman lost a great deal of blood, not so much by active hæmorrhage as by a kind of oozing. A couple of silver wires were put in, and she was placed in bed, but never rallied, and died in forty-eight hours. His reasons for performing the operation were, first, the great size of the tumour; secondly, the great amount of hemorrhage from which she suffered; and, thirdly, the repeated miscarriages which she had sustained.

Dr. PUREFOY communicated a case of successful Removal of the Right Uterine Appendage and Parovarian Tumour in a case of dysmenorrhcea and dyspareunia. He should add that the tumour had been for years of the same size. The ovaries presented the appearance of a slight amount of cystic disease.

Dr. JOHN BYRNe communicated a case of peri-uterine hrematocele, which was treated by tapping and eventuated in recovery. The case was illustrated by a very accurate drawing, made by Professor Birmingham.

Dr. BYRne also showed specimens of Malignant Disease of the Uterus from a case which proved fatal. The woman, who was aged about fifty, came to the hospital in a very blanched condition in consequence of hæmorrhage. A small malignant growth was found springing from the uterus. There was a great deal of hremorrhage from the growth, which was repressed. A large tumour was also found, which was evidently fluid, occupying the suprapubic, left iliac, and lumbar regions. This was quite movable. Malignant disease of the uterus was diagnosed, complicated with a cyst, which was probably malignant The woman was healthy in every other way. He resolved to remove both the uterus and cyst by abdominal section but forty-eight hours before her death she had a rigor, accompanied with great pain; her abdomen became very trmpanitic; and she complained of great difficulty of breathing, and sank. On post-mortem opening of the 